\title{
Olhares Sobre a Infância e o Teatro: Minha formação continuada na Trupe da Alegria
}

\author{
Diego de Medeiros Pereira \\ Universidade do Estado de Santa Catarina - UDESC/SC, Brasil \\ E-mail: diego.pereira@udesc.br
}

\section{Resumo}

Este texto trata de uma reflexão sobre diferentes modos de se conceber as crianças e suas infâncias. A partir de um projeto de formação continuada desenvolvido com profissionais da Educação Infantil no município de Florianópolis, o autor explora relações entre teorias sobre a infância e práticas artístico-pedagógicas desenvolvidas com crianças. $O$ trabalho teatral e de pesquisa realizado pela Trupe da Alegria - grupo de teatro composto por professoras de crianças - subsidia as análises desenvolvidas. Parte-se da Sociologia da Educação, passando-se pela Psicologia do Desenvolvimento para se chegar à Sociologia da Infância. As discussões buscam enfatizar as crianças como sujeitos produtores de cultura, cujas vozes deveriam ser apropriadas nas práticas pedagógicas, produções artísticas e pesquisas na área teatral.
This text is a reflection about different ways of conceiving children and their childhoods. From a teacher training project developed with Early Childhood Education professionals in the city of Florianópolis, the author explores relationships between theories about childhood and artisticpedagogical practices developed with children. The theatrical and research work carried out by Trupe da Alegria - a theater group composed of children teachers - supports the analyzes developed. It starts from the Sociology of Education, passing through Developmental Psychology to arrive at the Sociology of Childhood. The discussions seek to emphasize children as subjects that produce culture, whose voices should be appropriated in pedagogical practices, artistic productions and research in the theatrical area.

Pedagogia do teatro. Teatro com crianças. Infância. Formação de Professoras.

Theater pedagogy. Theater with children. Childhood. Teacher training. 


\section{O Ponto de Partida}

Após 10 anos como coordenador de um grupo de teatro formado por profissionais da Educação Infantil da cidade de Florianópolis/SC, de ter desenvolvido diferentes trabalhos que exploraram as relações entre teatro e infância, do contato contínuo com profissionais do "chão de sala", pensei em escrever um texto que, mais do que comemorar esses anos de (re)existência do grupo, pudesse materializar nossas descobertas e aprendizados coletivos.

Para além de um trabalho de pesquisa específico, esse projeto de formação continuada - e as experiências dele originadas - impulsionou diferentes investigações teóricas, propostas de criação artística, de formação pedagógica além de gerar referenciais metodológicos para se explorar a linguagem teatral com crianças.

A proposta de constituição de um grupo de teatro com professoras da Educação Infantil que fosse, ao mesmo tempo, uma formação continuada para as profissionais participantes e um laboratório para criação de trabalho voltados ao público infantil, nasceu em 2008, quando, após atuar como formador da rede municipal, prestei o processo seletivo para o mestrado em Teatro. O grupo Trupe da Alegria foi, então, criado em 2010, como objeto de estudo da minha dissertação. De lá para cá, foram 05 espetáculos, mais de 50 profissionais que já participaram de algum trabalho, o contato com muitas crianças expectadoras, incontáveis horas de encontros, ensaios, formações, discussões e trocas de saberes.

Buscarei, neste texto, refletir sobre a modificação do meu olhar acerca das crianças e suas infâncias, a partir dos diferentes vínculos teóricos que estabeleci ao longo dos anos impulsionado pelos trabalhos desenvolvidos junto às profissionais que compõem o grupo. Compreendo que, assim como as professoras, eu também estive em um processo continuado de formação sobre os modos de se explorar e pensar as práticas artístico-pedagógicas desenvolvidas com crianças.

Em um primeiro momento, estabelecerei relações com a Sociologia da Educação - em diá- logo com Pierre Bourdieu (1930-2002) - pois, assim como meu incipiente modo de ver as crianças no início de minhas pesquisas, ele apresenta um forte vínculo entre escola e criança, ou seja, as crianças entendidas a partir de seu ofício como "alunas" e, nesse sentido, revejo como o foco do início do trabalho da Trupe recaía na ampliação do capital cultural das profissionais com o objetivo de que elas pudessem, mediante a instituição escolar, ampliarem o repertório das crianças.

$\mathrm{Na}$ sequência, desvelo as descobertas em torno de processos de apropriação da linguagem teatral por parte das crianças; um segundo momento do trabalho em conjunto com a Trupe no qual investigamos a abordagem pedagógicoteatral do Drama estabelecendo paralelos com a psicologia do desenvolvimento, sobretudo a partir dos estudos de Lev Vygotsky (1986-1934).

Por fim, aponto as últimas investigações às quais tenho me dedicado, em uma aproximação com a Sociologia da Infância. Mediante leituras de Manuel Sarmento compreendo melhor os diferentes demarcadores que atravessam as crianças, suas infâncias e seu papel ativo como agentes produtoras de cultura e, nesse sentido, como nossas práticas artísticas e pedagógicas podem buscar a presença mais efetiva das crianças.

Nas pesquisas que se desafiam a explorar os limiares entre arte e educação, essas diferentes vertentes - Sociologia da Educação, Psicologia do Desenvolvimento e Sociologia da Infância - apontam para distintos modos de conceber as crianças e seus processos de criação. Intento, desse modo, elucidar como o meu olhar e minha prática - docente e artística - se alteraram em função dessas diferentes lentes teóricas, influenciando o trabalho desenvolvido junto às profissionais da Trupe da Alegria.

\section{- A ampliação do capital cultural das crianças \\ A Trupe da Alegria surgiu da percepção de que havia uma demanda por parte das profissionais que atuam com crianças na cidade de Florianópolis/SC de melhor compreenderem as especificidades do tra-}


balho com a linguagem teatral. Mediante os cursos de formação continuada que ministrei nos anos 2008 e 2009 - e em anos seguintes também - constatava que havia (e em certa mediada ainda há) uma carência por parte dessas docentes de conhecimentos que as auxilie na estruturação de propostas artístico-pedagógicas que explorem elementos do teatro, sem que haja, necessariamente, a criação de um produto cênico a ser compartilhado com um público - geralmente os pais e mães em datas comemorativas - ou que esse possa ser o resíduo de um processo de criação e investigação instigante e prazeroso para as crianças e professoras.

Diante disso, ofereci um curso de 05 meses de duração para as profissionais interessadas, entre os meses de abril e agosto de 2010. Aparecerem 52 professoras, das quais selecionei 20 - por conta de demandas de espaço e da dinâmica da proposta - permaneceram 14 até a finalização do processo, que resultou na criação de um espetáculo - a partir do desejo delas de compartilharem algo com as crianças. A vontade de seguir com a formação continuada em teatro originou o grupo Trupe da Alegria. Como destaquei em um escrito sobre o processo:

\begin{abstract}
Não se tratou de uma proposta de ensinar a esses professores "como" fazer teatro, mas de construir, por meio de experimentações, modos de pôr em contato conteúdos da prática educacional desses professores com os universos teatral e infantil. Acredito que processos como este possam favorecer o desenvolvimento das potencialidades artísticas dos profissionais da Educação Infantil, ampliando seus conhecimentos sobre o processo de ensino, aprendizagem, formas e fruição artísticas. (PEREIRA, 2015a, p. 18).
\end{abstract}

Por mais que o foco do trabalho, naquele momento, não fosse diretamente a criança, mas as possibilidades de trabalhos com a linguagem teatral que as professoras poderiam desenvolver com e para elas após sua participação no grupo, percebo que meu modo de conceber as crianças era mediado pela figura do adulto, ou seja, ampliar as experiências das professoras, consequentemente, ampliaria as das crianças. Hoje reconheço que havia um reducionismo nesse olhar, ao desconsiderar que as crianças são atravessadas por diferentes experiências; que seus modos de ser no mundo não se resumem às suas existências como "alunas". Ainda que minha preocupação fosse com os modos como as crianças são iniciadas na linguagem teatral, não reconhecia, naquele momento, referenciais teóricos que pudessem contribuir para que eu elegesse as crianças como objetos de estudo; mas, sim, suas professoras.

Meus primeiros vínculos teóricos em relação à infância se deram com a Sociologia da Educação. Essa disciplina se ocupa das relações entre escola e sociedade, debruçando-se, em geral, aos modos como as crianças são educadas, mediante processos de internalização de conhecimentos, normas e condutas. A escola é entendida como o "lugar da criança" que a modelará para a vida adulta - uma maturação - como se fosse esse o objetivo fim da vida social e as crianças, nesse contexto, são compreendidas a partir de seu papel como "alunas" e da necessidade de "socialização". Segundo Marchi:

Nas sociologias da família e da educação, até os anos 90, a infância e a criança eram sempre consideradas a partir das instituições que as erigiram na modernidade (a família, a escola). Isto é, nestas disciplinas, a infância/criança eram objetos subsumidos ou indiretos de análise, sendo investigadas através das instituições sociais que têm por função a sua socialização. Neste sentido, o foco da investigação esteve sempre voltado a estas instituições e aos processos de socialização e nunca à infância ou às crianças elas mesmas. (MARCHI, 2010, p. 187).

E a autora afirma ainda: [...] a socialização da criança como processo vertical de inculcação e transmissão de valores e saberes aos 'imaturos' visando sua formação em indivíduos plenamente adaptados ao meio social a que estão destinados. (MARCHI, 2010, p. 193). Dada a realidade social e cultural de muitas crianças - principalmente aquelas que frequentam creches públicas, em geral advindas das classes menos favorecidas - eu via 
as professoras da Educação Infantil como responsáveis por inserir as crianças em um universo cultural mais amplo alargando o "capital cultural" dessas. De fato, nossa preocupação continua sendo a de ampliar os repertórios das crianças, mas considerando que há uma série de saberes advindos das relações extraescolares que não são menos importantes que aqueles eleitos pelas instituições e redes de ensino e de que as vozes das crianças são importantes no processo de organização e experimentação de uma proposta artística.

Meu principal encontro com a Sociologia da Educação se deu por intermédio de Pierre Bourdieu que, em 1970, juntamente com Jean-Claude Passeron, escreveu o livro $A R e$ produção. Ao citar esses autores, apontei que:

\begin{abstract}
Para os autores, toda "ação pedagógica" é uma "violência simbólica", uma imposição arbitrária que é apresentada àquele que sofre a violência de modo dissimulado, ocultando as forças que estão na base de seu poder, um poder arbitrário que possui um determinado "arbitrário cultural", uma concepção cultural da elite, que é considerada como naturalmente e objetivamente superior às demais, que é imposta a toda sociedade por meio do sistema de ensino. (PEREIRA, 2011, p. 25)
\end{abstract}

Ainda que esses autores tenham se dedicado a pesquisar aspectos sociológicos relativos ao sistema educacional francês do final do século $X X$, via em seus estudos e escritos discussões e conceitos que poderiam ser apropriados na minha prática com as professoras, por retratarem um panorama da educação que dialogava, e em parte ainda dialoga, com a realidade educacional brasileira.

$\mathrm{Na}$ noção de "reprodução", está implicado o poder oculto da escola que passa a exercer sua função de reiterar as desigualdades sociais. "Tratando, formalmente, de modo igual, em direitos e deveres, quem é diferente, a escola privilegiaria, dissimuladamente, quem, por sua bagagem familiar, já é privilegiado" (NOGUEIRA; NOGUEIRA, 2006, p. 86). Nesse sentido, compreender os mecanismos que reproduzem as desigualdades sociais e de acesso nos auxiliaria na busca por ações que facilitassem o acercamento das crianças aos saberes culturalmente eleitos como significativos.

Bourdieu (1998) assinala a família como a maior responsável pela inserção do indivíduo em um determinado patamar cultural, uma vez que ela "socializa" as crianças antes dessas entrarem na escola, e, quando isso ocorre, tais crianças já possuem um patrimônio cultural, uma "herança" de valores, crenças, conhecimento de obras artísticas e literárias, habilidades para falar em público, postura corporal, em suma, possuem um universo social que identificam como seu e com o qual conseguem se relacionar com maior facilidade. Para se referir a essa "herança" familiar, Bourdieu criou o conceito de "capital cultural".

Dado o contexto da Educação Infantil, em que crianças com poucos meses de idade são postas nas creches, em geral, permanecendo cerca de 08 horas nesse ambiente, o qual será uma fonte diversa, daquela familiar, na constituição de seu capital cultural. Podemos falar, então, em um "capital híbrido" formado pelas referências familiares e escolares, nessas últimas contidos os saberes de outras crianças e, sobretudo, o capital posto à disposição pela professora que estiver em contato com essas crianças a maior parte do tempo.

Parece-me que o principal desafio, ao dialogar com essa teoria, é compreender que o universo escolar, em geral, apresenta às crianças uma visão hegemônica de cultura, de acordo com os interesses materiais e simbólicos daqueles/as que definem os currículos. São inseridos padrões linguísticos, comportamentais, culturais, entre outros - obviamente que com variações consideráveis se analisadas as diferenças estruturais entre o ensino público e o privado, por exemplo - observado esse fato, conclui-se que a escola reproduzirá os diferentes capitais culturais das classes sociais e, consequentemente, reproduzirá as próprias classes sociais dentro do ambiente escolar.

Nessa busca pela "formação" de uma criança "padrão" que deverá possuir um capital cultural previamente definido - os ditos "conhecimentos univer- 
sais" - o "fracasso" ou "sucesso" das crianças na escola dependerá da distância de suas heranças culturais em relação à cultura preconizada pela escola. Bourdieu afirma ainda que é necessário

[...] obrigar e autorizar a instituição escolar a desempenhar a função que the cabe, de fato e de direito, ou seja, a de desenvolver em todos os membros da sociedade, sem distinção, a aptidão para as práticas culturais que a sociedade considera como as mais nobres. (BOURDIEU, 1998, p. 62).

Fora isso, parece-me que a escola necessita perceber as crianças para além de seus "objetivos de aprendizagem" e da necessidade de que elas respondam de modo formatado às suas demandas; tratar as crianças como sujeitos sociais, já socializadas, pertencentes a uma determinada categoria geracional - a infância, essa dotada de especificidades e culturalmente diversa da geração adulta. O teatro, nesse sentido, é um componente curricular bastante aberto às vozes e manifestações das crianças que requer suas participações ativas e afetivas impulsionando o trabalho artístico. Ainda que, muitas vezes, caíamos na tentação de definir os rumos de uma proposta sem levar em conta as crianças.

As ideias de Bourdieu se tornam contemporâneas na medida em que são percebidas as novas configurações que se formam na constituição de sujeitos com múltiplas referências (família, escola, mídia, etc.) ao mesmo tempo em que nos alerta para a necessidade de revermos nossas práticas pedagógicas para que essas não estejam centradas em uma ideia de "adaptação" das crianças a um meio social determinado. Para Nogueira e Nogueira "[...] ao sublinhar que a cultura escolar está intimamente associada à cultura dominante, a teoria de Bourdieu abre caminho para uma análise crítica do currículo, dos métodos pedagógicos e da avaliação escolar." (2006, p. 94).

Os dois primeiros espetáculos da Trupe-Uma creche divertida e colorida (2010) e Brasil de todas as cores (2011 e 2012) - estavam centrados nessa ideia de ampliar os repertórios das crianças, de lhes ofere- cer uma experiência de fruição, de estabelecer contatos iniciais com a linguagem teatral. Havia um olhar voltado à responsabilidade da escola e, nesse sentido, reduzia-se a uma visão das crianças como "alunas". Aos poucos, fomos nos deparando com outras necessidades e desejos que nos levarem a (re)conhecer outras perspectivas teóricas sobre a infância.

\section{O desenvolvimento infantil} e a apropriação da linguagem teatral

Ao longo dos primeiros anos de trabalho com a Trupe, vários eram os momentos em que as professoras me perguntavam "como aplicar essas práticas com as crianças". A primeira resposta era a de que eu não aplicava nada, porque a experimentação teatral não é algo unilateral que "aplicamos" em alguém e, na sequência, nós discutíamos as possibilidades de adaptação dos exercícios que experimentávamos para uma proposta pedagógica com crianças.

Essas indagações quanto à uma abordagem que se aproximasse das especificidades da infância me levou ao doutorado e, como consequência, à psicologia do desenvolvimento. Essa área de estudos tem ocupado um lugar central quando se trata de discussões voltadas aos processos de ensino-aprendizagem do teatro para crianças.

Obras de grande importância para a área da Pedagogia do Teatro - especificamente tratando de crianças - fazem diálogo direto com a Psicologia do Desenvolvimento. Dentre elas é possível citar:

- o livro Jogos Teatrais (1984), da professora Ingrid Koudela, no qual, fundamentada nos estudos de Jean Piaget (1896-1980), a autora procura comprovar a origem do teatro no jogo infantil, defendendo a potencialidade do teatro no desenvolvimento intelectual, social e afetivo das crianças. Koudela se utiliza dos Jogos Teatrais de Spolin ${ }^{1}$ para discutir a apropriação da linguagem teatral pelas crianças;

1 Viola Spolin (1906-1994). Autora e diretora de teatro e criadora do sistema Jogos Teatrais, metodologia de atuação amplamente difundida que parte de jogos de improvisação para a apropriação técnica de elementos do teatro. 
- o trabalho da professora Vera Lúcia Bertoni dos Santos, detalhado no livro Brincadeira e conhecimento: do faz-de-conta à representação teatral (2004), no qual ela discute aspectos relacionados à maneira como os trabalhos com elementos dramáticos e teatrais têm sido desenvolvidos no âmbito da Educação Infantil. Apoia-se, também, na teoria piagetiana para fundamentar e discutir a passagem da brincadeira de faz de conta para a representação teatral. Além disso, a autora traz exemplos tanto de sua vida pessoal quanto de entrevistas realizadas com crianças para demonstrar o modo como esse processo de desenvolvimento se dá;

- a obra A linguagem teatral na escola (2007) de Ricardo Japiassu, que dialoga com a concepção de Lev Vygotsky do desenvolvimento humano. A concepção histórico-cultural, como ficou conhecida, tem como foco de estudo o desenvolvimento do indivíduo e da espécie humana como resultado de um processo sócio histórico, no qual as relações que os sujeitos estabelecem com a realidade circundante seriam responsáveis por seus processos de construção de conhecimento. Japiassu apresenta algumas propostas de trabalho com Jogos Teatrais spolinianos a partir dessa perspectiva. Por conta da crítica de Vygotsky à tentativa da psicologia de definir características e leis universalmente válidas para o desenvolvimento humano, no momento de escolha de referenciais para a tese percebi na teoria histórico-cultural um caminho possível de diálogo, por considerar, de maneira mais direta, o contexto histórico e cultural no processo de desenvolvimento das crianças, assim como por avistar uma aproximação com a teoria e a prática do Drama $^{2}$ que foi meu objeto de estudo no doutorado: a

2 O Drama é uma abordagem inglesa para o ensino e a experimentação do teatro, difundida no Brasil pela professora Beatriz Ângela Vieira Cabral. Seu livro "Drama como método de ensino" (2006) é a principal referência no país para compreensão dessa proposta. defesa de que o Drama - dentre as abordagens mais difundidas na era da Pedagogia do Teatro no Brasil melhor se aproxima das especificidades da infância.

A teoria histórico-cultural (também conhecida como sócio histórica ou sócio interacionista) teve início com as obras de Lev Vygotsky desenvolvidas em meio à revolução socialista russa, ocorrida em 1917, e à ditadura socialista da União Soviética.

Rego (2013) cita as palavras de Vygotsky para apontar o objetivo central dos estudos desse autor: "[...] caracterizar os aspectos tipicamente humanos do comportamento e elaborar hipóteses de como essas características se formaram ao longo da história humana e de como se desenvolvem durante a vida de um indivíduo" (2013, p. 38). A abordagem vygotskiana, portanto, vai definir o sujeito como um ser construído a partir da apropriação e reelaboração de ações, conceitos e signos historicamente e socialmente construídos; nessa concepção, a cultura integra a natureza humana.

Para verificar a possível apropriação do Drama pela Educação Infantil, em 2013, propus às profissionais da Trupe da Alegria a realização de 09 processos de Drama nas unidades educativas onde trabalhavam. Esses trabalhos foram orientados semanalmente por mim, mas conduzidos pelas profissionais; umas trabalharam em duplas (com outra membra da Trupe que não estivesse em sala) enquanto outras inseriram parceiros/as de suas unidades no processo (como uma maneira de disseminar essa proposta a outras profissionais). Dividimos os processos por faixas etárias: $03 \mathrm{com}$ crianças de 02 e 03 anos, 03 com crianças de 04 e 05 anos e outros 03 com crianças de 06 anos. Paralelo aos processos de Drama, desenvolvíamos nosso terceiro espetáculo, Navegando à terras distantes (2013 e 2014) ${ }^{3}$, que buscava, também, dialogar com aspectos dessa abordagem.

3 No texto "Navegando à Terras Distantes": teatro contemporâneo para crianças" (2019) apresento detalhes desse trabalho, assim como reflexões sobre diálogos entre práticas teatrais contemporâneas e o teatro para crianças. 
Com a tese, conseguimos encontrar e defender uma proposta metodológica que pudesse orientar ações pedagógico-teatrais direcionadas às crianças, apontando estratégias de trabalho passíveis de serem desenvolvidas com diferentes faixas etárias e dialogando com as "atividades" de maior interesse das crianças em cada um desses grupos etários, em diálogo com o discutido por Vygotsky e seus colaboradores. E concluí:

Por ser uma referência metodológica que parte do contexto dos participantes, o Drama se apresenta como uma possibilidade de trabalho que estabelece um diálogo constante com a realidade e, nesse sentido, com o contexto artístico e educacional contemporâneo não isolando a arte produzida fora dos muros da escola, podendo dialogar com as transformações artísticas, políticas, sociais, culturais e histórias. Por se apropriar das falas, desejos e curiosidades dos sujeitos ele se coloca como uma referência atual e em constante renovação que consegue se utilizar das brincadeiras de faz de conta infantis transpondo-as a um fazer teatral paulatinamente tornado consciente pela criança. (PEREIRA, 2015b, p. 291).

A defesa da tese, em 2015, o contato mais próximo com as crianças, advindo tanto dos trabaIhos com a Trupe quanto das orientações de estágio com Educação Infantil no curso de Licenciatura em Teatro da Universidade do Estado de Sana Catarina (UDESC), as aulas ministradas no curso de Pedagogia dessa instituição, as formações continuadas com diferentes grupos de professoras da Educação Infantil, além do desenvolvimento de projetos voltados a práticas teatrais com e para crianças, levaram-me a investigar, cada vez mais, as discussões teóricas sobre a infância. Nesse caminho, deparei-me com diferentes críticas à psicologia do desenvolvimento, como as de Hillesheim e Guareschi:

As teorias sobre o desenvolvimento humano têm se caracterizado pela constituição de saberes que pressupõem uma concepção de tempo linear, cumulativo, vazio e homogêneo, cujo desdobramento se dará no futuro. Nessa perspectiva, a infância é compreendida como um mero estado de passagem, que deve ser superado a partir da acumulação de experiências e conhecimentos necessários à vida adulta. Essa linearidade confere à infância uma condição de menoridade, visto seu estado transitório, inacabado e imperfeito, em contraposição à idade adulta, marcada como um tempo de estabilidade e maturidade. (HILLESHEIM; GUARESCHI, 2007, p. 86).

Posto isso, passei a me questionar acerca da outra homogeneização que, diferente da Sociologia da Educação que se apoiava na escola para a inserção das crianças nas normas e cultura adultas, agora se apoia no desenvolvimento biológico para reafirmar o adulto como fim; uma imaturidade biológica que tem como padrão esse adulto e, nesse sentido, desconsidera a infância como um momento em si, entendendo-a como uma etapa "natural" e universal da existência humana (SIMÕES; PERES; QUEIROZ, 2018). "Pressupõe-se, assim, a universalidade das trajetórias da vida humana, minimizando-se as diferenças e maximizando as semelhanças entre os sujeitos [...]" (HILLESHEIM; GUARESCHI, 2007 , p. 85). O risco de se tratar essa "criança" no singular, é não se desconsiderar os diferentes demarcadores que as atravessam: classe social, cor, gênero, deficiências, constituição familiar, cenário político, religioso, cultural, geográfico, entre outros.

São inegáveis as contribuições da Psicologia do Desenvolvimento para se pensar as crianças e se desenvolver experimentações que possam trazer indícios de suas formas de pensamento e linguagem. É sempre importante ressaltar que as teorias são situadas em um determinado tempo histórico e estão sujeitas aos limites de pensamento de sua época. Problematizar as teorias psicológicas sobre as crianças é possibilitar que outras formas de compreensão da infância possam emergir e que outros paradigmas teóricos possam ser tomados como suporte de análise.

[...] a concepção de estágios de desenvolvimento seria a marca da racionalidade adultocêntrica que não 
reconhece a criança e a infância no presente, mas a criança como um ser em devir e a infância como uma passagem, uma transição e que focaliza o desenvolvimento como processo que ocorre no indivíduo. (SIMÕES; PERES; QUEIROZ, 2018, p. 06).

Ao se dialogar com essas teorias para analisar práticas teatrais, no meu ponto de vista, necessita-se compreender que as condições socioculturais exercem influência sobre o curso do processo; que os "limites" de idade dependem das condições históricas, logo, eles se alteram com a mudança dessas condições. Entendo como importante observar as crianças em seus tempos e espaços, compreendendo a infância como um fenômeno social específico e, ao mesmo tempo, múltiplo.

Ao adentrar, cada vez mais, nos Estudos da Infância, tenho encontrado discursos que tomam as crianças como atores sociais de pleno direito, com características específicas, por conta de sua idade (PINTO; SARMENTO, 1997). A Sociologia da Infância defende que cada infância é vivida de modo diferente e, nesse sentido, busca quebrar padrões do que é ser criança ou os modos de viver a infância, aprofundando suas possibilidades e potencialidades de ser e de criar, sem colocarmos a nós - adultos - como comparativo ou padrão de desenvolvimento desejado.

\section{- As crianças como produtoras de cultura}

A Sociologia da Infância vem se consolidando no campo científico desde os anos de 1990 propondo novos paradigmas e arcabouços conceituais para se estudar as crianças e suas infâncias. No centro desse campo de estudos, está a compreensão de que a noção de infância é uma construção histórico-social e, nesse sentido, pode ser estudada como um fenômeno social; uma categoria geracional ocupada pelas crianças.

Perceber a criança, além do lugar social de filho ou aluno, permite entendê-la como ator social. Assim, a infância passa a ser entendida como construção social e não apenas como uma etapa da vida caracterizada por aspectos biológicos, incapacidades e ausências. (SIMÕES; PERES; QUEIROZ, 2018, p. 02-03).

\section{Segundo Pinto e Sarmento,}

[...] "ser criança" varia entre sociedades, culturas e comunidades, pode variar no interior da fratria de uma mesma família e varia de acordo com a estratificação social. Do mesmo modo, varia com a duração histórica e com a definição institucional da infância dominante em cada época. (PINTO; SARMENTO, 1997, p. 17).

Instigados/as por esse olhar sobre a infância como construto social de uma determinada época e contexto, criamos o espetáculo Circo Normalóides (2015 e 2016) que buscava, por meio de seus quadros circenses, descontruir padrões de comportamento esperados das crianças, assim como estereótipos de gênero, de "família tradicional", de música "infantil" impostos pela nossa sociedade. Junto disso, com algumas professoras da Trupe cursando mestrado em Educação, passamos a discutir nos encontros do grupo a noção de "culturas infantis": "[...] o reconhecimento da capacidade de produção simbólica por parte das crianças e a constituição das suas representações e crenças em sistemas organizados, isto é, em culturas" (PINTO; SARMENTO, 1997, p. 20).

Entendo que essa noção é bastante cara para pensarmos nossas práticas artístico-pedagógicas com crianças. Por mais que tenhamos uma literatura na área de Pedagogia do Teatro que indique possíveis respostas das crianças às proposições que realizamos, as produções de sentidos por parte das crianças estarão impregnadas pela pluralidade de sistemas simbólicos que as (con)formam. Que teatro é feito pelas crianças? Quais as suas referências? Como não projetarmos nas produções das crianças as nossas expectativas, mas realizarmos um processo de auscultação das vozes das crianças? (PINTO; SARMENTO, 1997). Como não fazer delas "fantoches" de uma criação, invisibilizando suas participações no processo e suas produções artísticas? 
Marchi (2010) ao citar Sarmento (2006), aponta que a "invisibilidade" da infância possui uma razão de "natureza social" e outra de "natureza epistemológica":

A primeira diz respeito tanto à "privatização" ou confinamento da infância ao espaço doméstico ou às instituições sociais de educação e guarda (escolas, asilos, creches, orfanatos, etc.) quanto à "subalternidade" das crianças relativamente ao mundo dos adultos e à sua concepção de seres incompletos ou "em trânsito" para a idade adulta (o que explicaria sua presença inicial nas ciências médicas, na psicologia e na pedagogia). A segunda razão, de ordem epistemológica [...] diz respeito às críticas realizadas pela $\mathrm{SI}^{4}$ às teorias clássicas da socialização no âmbito da psicologia do desenvolvimento. (MARCHI, 2010, p. 185).

Por conta de necessidade de compreendermos melhor esse outro modo de ver as crianças - como seres completos - e de assegurar a elas uma participação nas práticas artísticas e pedagógicas, criamos, em 2017, o Grupo de Estudos sobre Teatro e Infâncias (GETIs). O grupo, formado por graduandos/as dos cursos de Licenciatura em Teatro e Bacharelado em Artes Cênicas da Universidade Federal de Santa Maria (UFSM), reunia-se, duas vezes por semana - uma dedicada ao estudo de referenciais teóricos sobre teatro e infância e a outra à elaboração de um experimento cênico com abertura para que as crianças pudessem dividir a cena com os/as performers ${ }^{5}$.

Entre os anos de 2017 e 2019 - quando estive afastado de Florianópolis - a Trupe criou e apresentou o espetáculo $A$ Fantástica Exposição de Zeca ${ }^{6}$ que mesclava personagens da literatura infantil universal - como Branca de Neve, Lobo Mal, Pinóquio, Rainha de Copas - com personagens de literaturas não clássicas, trazendo à cena prin-

$4 \mathrm{SI}$ - Sociologia da Infância.

5 Detalhes sobre o espetáculo "Atenção para a Chamada!", criado pelo GETIs, podem ser encontrados no texto "A Brincadeira como Performance em um Espetáculo para Crianças" (2019).

6 Espetáculo dirigido em parceria com a professora e atriz Thaís Ortigara Putti. cesas africanas, indianas, guerreiros/as indígenas, maoris, entre outros, buscando desvendar em cena diferentes culturas, literaturas e práticas culturais.

Mesmo à distância, nossas discussões e pesquisas buscavam as crianças, olhá-las como parceiras, como agentes de sua formação e da de seus pares. Muitas questões nos perseguiam (e ainda nos perseguem): como descentralizar nosso olhar de adultos para perceber os modos como as crianças criam? Como não projetar nas ações das crianças imagens criadas por nós e não por elas? Como registrar as manifestações, investigar os indícios, coletar as vozes e expressões, os sentidos por elas produzidos para que nossas pesquisas em arte/teatro possam, de fato, incorporar as manifestações das crianças? Como não deixar que nossa visão adultocentrada contamine nossas pesquisas com crianças? Como ampliar os modos de participação das crianças nas práticas teatrais? São muitas questões que não se esgotam, pelo contrário, alimentam novos escritos, reflexões e práticas que buscam se aproximar das crianças.

Em 2020, por convite da professora Sandra Mara da Cunha, participei do Núcleo de Estudos em Música, Educação e Infância - MEl. O objetivo inicial do grupo era reunir estudantes e professores/ as interessados/as em se aproximar dos conceitos e produções bibliográficas de pesquisadores e pesquisadoras da Infância. Nesse grupo pude ter um contato mais efetivo - mediado por Sandra - com as discussões da Sociologia da Infância, sobretudo aproximando-a da área de Artes, de modo mais específico da música e do teatro.

Ao retratar o modo como tem atuado nessa busca por conceber as aulas de música a partir de uma assimilação das propostas de participação infantil advindas da Sociologia da Infância, Cunha afirma que:

Do ponto de vista da cotidianidade das aulas, na convivência com seus professores e colegas, as crianças têm espaço para emitir suas opiniões. Elas são estimuladas a defender suas ideias e pontos de vista, fazem escolhas relativas a tempos, espaços, optam por materiais e modos de organizá-los, em 
conjunto ou individualmente. Elas também tomam parte nas decisões sobre como apresentar seus trabalhos nas mostras que acontecem o tempo todo na escola; decidem até mesmo que não desejam apresentar seus trabalhos. (CUNHA, 2017, p. 52-53).

Esse modo de se relacionar com as crianças, em que elas se tornam parceiras do processo, em que seus repertórios, interesses e opiniões são considerados, abre a possibilidade de que as crianças ao mesmo tempo em que se apropriam da cultura, possam, constantemente, (re)cria-la. Como aponta Cunha: "[...] as concepções estéticas das crianças, muitas vezes distintas das minhas, caracterizam um desafio a ser constantemente enfrentado. Como acolher suas opções estéticas? Como orientar sem desconsiderar outras visões estéticas e de mundo?" (2017, p. 55).

A potencialidade do teatro em ofertar esses espaços/tempos de interação com propostas em que as crianças possam tanto dialogar e criar com seus pares crianças, quanto com seus pares adultos, é imensa. Sabemos que, em geral, as aulas de teatro requerem a participação dos sujeitos envolvidos em um processo de experimentação da linguagem para que a proposta aconteça. Como, entretanto, ampliar essa lógica para o trabalho pedagógico de toda a unidade escolar?

Para além disso, como pensarmos uma cena inclusiva, em que todas as crianças possam fruir a produção, a seu modo, a partir de suas potencialidades? No ano de 2020, por conta da pandemia de COVID-19, realizamos encontros virtuais com as professoras da Trupe. Nesses encontros, lançamo-nos o desafio de levantarmos materiais para criação de um novo espetáculo. No desenho inicial da proposta cênica, teremos 06 cenas paralelas - cada uma delas acontecendo com as faixas etárias de 00 a 06 anos - buscando, na medida do possível, agregar as respostas das crianças à nossa proposta artística.

Nas diferentes esferas de ação com as crianças - na cena, na sala de aula ou nas pesquisas acadêmicas - temos nos provocado a, cada vez mais, compartilharmos efetivamente o espaço - majoritariamente ocupado pelos adultos - para que as crianças tenham, de fato, um papel ativo, para que suas apropriações das "coisas" do mundo se deem a partir de suas necessidades e desejos, para que suas formas de expressarem sua (re)construção do mundo estejam em acordo com as suas formas de existência, consideradas em si mesmas, em transformação. Como apontam Simões, Peres e Queiroz: "As crianças criam e participam de suas próprias e exclusivas culturas de pares e selecionam ou se apropriam de informações do mundo adulto para lidar com suas próprias e exclusivas preocupações" (2018, p. 09).

Nesse sentido, pensar em uma proposta (artística, pedagógica, de pesquisa) requer, acredito eu, ferramentas que possam reconhecer e recolher as vozes das crianças, seus gestos e suas ações, tomando, sempre que possível, o cuidado para não falarmos por elas, para não projetarmos nossas aspirações em seus processos de criação, para não enxergarmos algo que não esteja ali, pra não impregnarmos seus movimentos de concepções adultas. É uma tarefa fácil? Com certeza não. É uma busca constante pela parceria, pela participação efetiva e afetiva das crianças, por considerá-las nas tomadas de decisão, por lhes perguntar sobre suas aspirações e sensações, por perceber seus movimentos, choros e olhares.

\section{Algumas considerações}

Ao revisitar o percurso da Trupe da Alegria, lançando olhares sobre os diferentes modos de conceber a infância que foram atravessando meu percurso como docente, artista e pesquisador, entendo que é necessário "desescolarizar" nosso modo de abordar as relações entre crianças e arte, descortinar as diferenças entre os grupos de crianças, mesmo àquelas pertencentes a um mesmo grupo etário, reconhecer que elas possuem uma cultura própria, delimitada pelos seus modos de perceber o mundo e se expressar nele.

Minha formação continuada junto a essas professoras me faz enxergar um caminho que aponta 
para uma abordagem interdisciplinar dos processos de aprendizagem e criação que busque, cada vez mais, contemplar em nossas pesquisas e práticas teatrais com e para crianças, suas vozes, anseios, desejos e formas de ver e (re)construir o mundo.

\section{Referências}

BOURDIEU, Pierre. A escola conservadora: as desigualdades frente à escola e à cultura. In: BOURDIEU, Pierre. Escritos de Educação. Petrópolis: Vozes, 1998.

CUNHA, Sandra Mara da. Quebra-cabeça sonoro: um jogo chamado criação musical. Orfeu [on-line]. v. 2, n. 2, 2017.

HILLESHEIM, Betina; GUARESCHI, Neuza Maria de Fátima. De que infância nos fala a psicologia do desenvolvimento? Algumas reflexões. Psicologia da Educação [on-line]. v. 25, n. 2, p. 75-92, 2007.

JAPIASSU, Ricardo. A linguagem teatral na escola: pesquisa, docência e prática pedagógica. Campinas, SP: Papirus, 2007.

KOUDELA, Ingrid. Jogos Teatrais. São Paulo: Perspectiva, 1986.

MARCHI, Rita de Cássia. O "ofício de aluno" e o "ofício de criança": articulações entre a sociologia da educação e a sociologia da infância. Revista Portuguesa de Educação [on-line]. v. 23, n. 1, p. 183-202, 2010.

NOGUEIRA, Cláudio Marques Martins; NOGUEIRA, Maria Alice. Bourdieu e a Educação. Belo Horizonte: Autêntica, 2006.

PEREIRA, Diego de Medeiros. Teatro na formação de professores da educação infantil. Curitiba: Editora Appris, 2015a.
PEREIRA, Diego de Medeiros. Drama na Educação Infantil: experimentos teatrais com crianças de 02 a 06 anos. 2015. 293 f. Tese (Doutorado em Teatro) - Programa de Pós-Graduação em Teatro, Universidade do Estado de Santa Catarina, Florianópolis, 2015b.

PEREIRA, Diego de Medeiros. Commedia dell'arte e educação infantil: um processo de formação de professores. 2011. 203 f. Dissertação (Mestrado em Teatro) - Programa de Pós-Graduação em Teatro, Universidade do Estado de Santa Catarina, Florianópolis, 2011.

PEREIRA, Diego de Medeiros; FAZZIONI, Mateus Junior. A brincadeira como performance em um espetáculo para crianças. Moringa Artes do Espetáculo [on-line]. v. 10, n. 1, p. 129-148, 2019.

PEREIRA, Diego de Medeiros; CLAUDINO, Simoni Conceição Rodrigues. Navegando à terras distantes: teatro contemporâneo para crianças. In: GOMES, Angela Maria (org.). Notas sobre literatura, leitura e linguagens 2. Ponta Grossa: Atena Editora, 2019.

PINTO, Manuel; SARMENTO, Manuel Jacinto. As crianças e a infância: definindo conceitos, delimitando o campo. In: PINTO, Manuel; SARMENTO, Manuel Jacinto. (Coords.) As crianças: contextos e identidades. Braga: Universidade do Minho, 1997.

REGO, Teresa Cristina. Vygotsky: uma perspectiva histórico-cultural daeducação. Petrópolis, RJ: Vozes, 2013.

SANTOS, Vera Lúcia Bertoni dos. Brincadeira e conhecimento: do faz-de-conta à representação teatral. Porto Alegre: Editora Mediação, 2004.

SIMÕES, Patricia Maria Uchôa; PERES, Flávia Mendes de Andrade e; QUEIROZ, Jacqueline Travassos de. O encontro entre a psicologia e a sociologia da infância. Psicologia em Estudo [on-line]. v. 23, p. 1-13, 2018. 
Recebido: 10/01/2021

Aceito: $22 / 04 / 2021$

Aprovado para publicação: 27/05/2021

Este é um artigo de acesso aberto distribuído sob os termos de uma Licença Creative Commons Atribuição 4.0 Internacional. Disponível em: <http://creativecommons.org/licenses/by/4.0>.

This is an open-access article distributed under the terms of the Creative Commons Attribution License 4.0 International. Available at: <http://creativecommons.org/licenses/by/4.0>.

Ce texte en libre accès est placé sous licence Creative Commons Attribution 4.0 International. Disponible sur: <http://creativecommons.org/licenses/by/4.0>. 